\title{
Seasonality in twin birth rates, Denmark, 1936-84
}

\author{
BIRGITTE BONNELYKKE ${ }^{1}$ JES SøGAARD $^{2}$, AND JOHANNES NIELSEN ${ }^{1}$ \\ From the Cytogenetic Laboratory, ${ }^{1}$ Arhus Psychiatric Hospital, and the Institute of Social Medicine, ${ }^{2}$ University of \\ Arhus, Denmark
}

SUMmARY A study was made of seasonality in twin birth rate in Denmark between 1977 and 1984. We studied all twin births $(N=45550)$ in all deliveries $(N=3679$ 932) during that period. Statistical analysis using a simple harmonic sinusoidal model provided no evidence for seasonality. However, sequential polynomial analysis disclosed a significant fit to a fifth order polymomial curve with peaks in twin birth rates in May-June and December, along with troughs in February and September. A falling trend in twinning rate broke off in Denmark around 1970, and from 1970 to 1984 an increasing trend was found. The results are discussed in terms of possible environmental influences on twinning.

A variety of environmental factors are known to influence pregnancy and childbirth. Of particular interest for the present study are previous reports on the seasonality of twin births. Some studies have shown an excess in twinning rates in the spring, ${ }^{12}$ some have shown an excess in the autumn and early winter months, ${ }^{3-5}$ and some found no evidence of seasonality in twinning rates. ${ }^{6-10}$ In a study dealing with twin conceptions, an excess was found in the spring and autumn. ${ }^{11}$

The influence of environmental factors on reproduction may be reflected in the fact that the dizygotic twinning rate has been falling during the last 30 to 40 years in every country where data have been available. ${ }^{12-14}$ This fall is one of the most pronounced changes in biological reproduction. Still we have only suppositions of the underlying mechanisms and no certain knowledge. Only part of this fall can be explained by maternal age and parity. ${ }^{14}$

The purpose of this study was to describe the pattern of seasonal variation if such variation existed in Danish twinning rates and thereby to obtain some hints concerning external factors leading to twin births.

\section{Methods}

Data on twin births and total births in Denmark were provided by Danmarks Statistik. The data covered the period from 1 January 1936 through 31 December 1984. They concerned all deliveries (live and stillborn, legitimate and illegitimate, $N=3679$ 932) in Denmark during that period and involved 45550 twin births. No information was available concerning twin zygosity, maternal age or parity for monthly data.
Twin birth rates (TBRs) were computed as follows: $\mathrm{TBR}_{\mathrm{t}}=\frac{\omega \mathrm{T}_{\mathrm{t}-1}^{1}+(1-\omega) \mathrm{T}_{t}^{1}}{B_{t}^{1} / 1000}$ for $\mathrm{t}=2, \ldots, 588$ $\mathrm{T}^{1}$ and $\mathrm{B}^{1}$ denote monthly twin and total birth frequencies, respectively, adjusted for length of month (ie, observed frequencies were multiplied by $30 \cdot 4 /$ number of days in month). A weight factor, $\omega$, was used to adjust for differences in mean gestational length between singleton and twin pregnancies. A mean difference of 20 days has been reported in the literature, ${ }^{15}$ which corresponds to $\omega=0.65$. It is seen from the formula above that the TBR for January 1936 is not available. In order to operate with an equal number of observations for each month the analysis of seasonality covers 1937 through 1984 only.

Secular trends in the TBR may confound the analysis of seasonal trends. Therefore, trend-adjusted monthly averages in TBR rather than crude averages were used. The data analysis is based on the following statistical model:

$$
\operatorname{TBR}_{t}=\sum_{i=1}^{12} \alpha_{i} D_{i}+\sum_{i=1}^{N T} \beta_{i}\left(\frac{t}{12}\right)^{i}+\varepsilon_{t}
$$

where

$\mathrm{t}=$ calendar time

$\beta_{i}=$ trend coefficients

$\mathrm{D}_{\mathrm{i}_{\mathrm{t}}}=\mathbf{a}$ month-dummy variable

$\alpha_{i} \quad=$ seasonal coefficients of the TBR

$\varepsilon_{\mathrm{t}} \quad=$ error term

NT $=$ order of time trend polynomial

The coefficients of the model were estimated by ordinary least squares methods. Next, intra-year 
variation in the TBR was tested through the nonparametric test suggested by Edwards, and the score test by Rogers, which is a modified version of Edwards' original test against cyclic behaviour. All three tests were based on the $\alpha$-coefficients and hence trend-corrected. However, a wide range of intra-year variation may be present in the TBR.

A more detailed picture of this intra-year variation can be revealed by subjecting the estimated coefficients to a nested series of hypothesis tests. Each hypothesis in the series imposes an additional restriction on the variation of the $\alpha$-coefficients. The restrictions are equivalent to polynomial constraints on the $\alpha$-coefficients. The unrestricted coefficients are equivalent to an 11 th degree polynomial pattern. The first null hypothesis in the nested series is an nth degree polynomial, $\mathrm{n}<11$. If this null hypothesis is accepted, we proceed to test a $(n-1)$ th degree polynomial, et cetera. The final null-hypothesis is a zero-degree polynomial, ie, that all seasonal coefficients lie on a flat line. This null hypothesis is equivalent to no intra-year variation. If we reject a (n-1) degree polynomial restriction, but have accepted the nth degree restriction, we can calculate the nth degree restricted seasonal coefficients, and they should provide a more precise estimate of the seasonal coefficients compared to the unrestricted coefficients.

\section{Results}

The number of twin births per 1000 pregnancies per year is shown in figure 1. The degree of the trend polynomial for the total period, 1937-84, was 3 , and the trend line shown as the dashed line in figure 1 . Note that this trend line is not calculated to provide projections but to provide a within-sample description of trends in the TBR data. The results of trend analysis for the three subperiods are reported in table 1 . There was no trend in the twin birth rate for the period 1937-48. For the period 1949-69, a very well determined linear trend coefficient of -0.16 was estimated, which means that the twin birth rate declined by $0 \cdot 16$ per 1000 each year. For the third

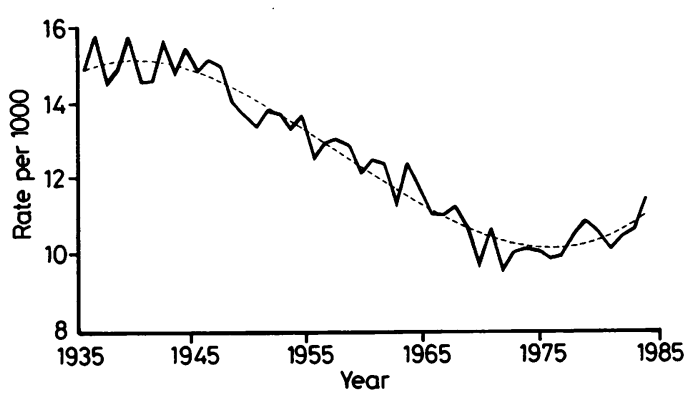

Fig 1 Twin births per 1000 births, Denmark, 1936-84

period, from 1970 to 1984 , a significant and increasing trend of 0.07 per 1000 was found.

The monthly averages for twin births are shown in figure 2. A peak in TBRs can be seen in the spring and early summer months as well as in December. The results of statistical analyses are shown in table 2 . No significant seasonality was found using either the method of Edwards or that of Rogers. However a significant excess of twin births between December and May from 1949 to 1969 and between May and October from 1970 to 1984 was shown by Hewitt's test.

The results of the nested testing procedure are reported in table 3 for the total period and for each of the three subperiods. The results suggest intra-year variation according to a fifth order polynomial curve for the periods 1949-69 and 1937-84. No systematic intra-year variation seems present for the other two subperiods.

The $\chi^{2}$ statistics reported in table 3 test the validity of the imposed restrictions. For each period we can accept a fifth degree polynomial restriction. For all periods but the $1970-84$ period a large increase in the $\chi^{2}$ value is observed when we proceed to a fourth degree polynomial. For the most restrictive alternative (a zero degree polynomial structure (no seasonality)) the $\chi^{2}$ statistics are nominally significant for the total period and the 1949-69 subperiod only. Real significance levels that are adjusted for carrying out seven

Table 1 Results of trend analysis for subperiods

\begin{tabular}{lccc}
\hline Statistics & $1937-48$ & $1949-69$ & $1970-84$ \\
\hline $\begin{array}{l}\text { Degrees of freedom } \\
\begin{array}{l}\text { Point of estimate } \\
\text { of trend coefficient }\end{array}\end{array}$ & 131 & 239 & 167 \\
$\begin{array}{l}\text { p-value } \\
\text { Ho: } \beta=0\end{array}$ & -0.007 & -0.161 & 0.071 \\
$95 \%$ confidence intervals & 0.814 & 0.00 & 0.0003 \\
\hline
\end{tabular}


1937 to 1984

1949 to 1969

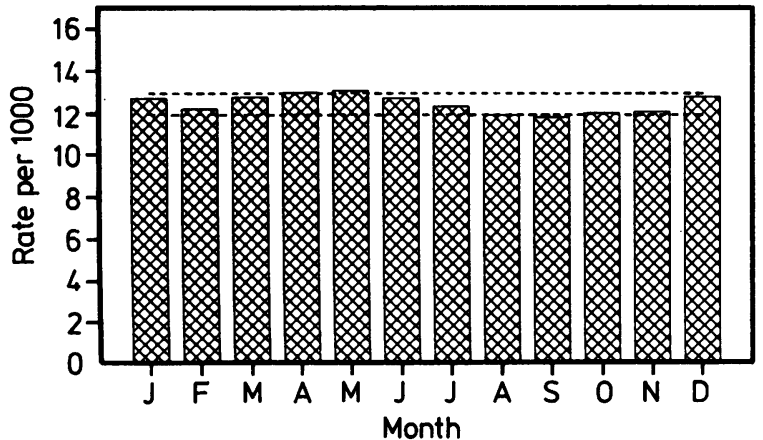

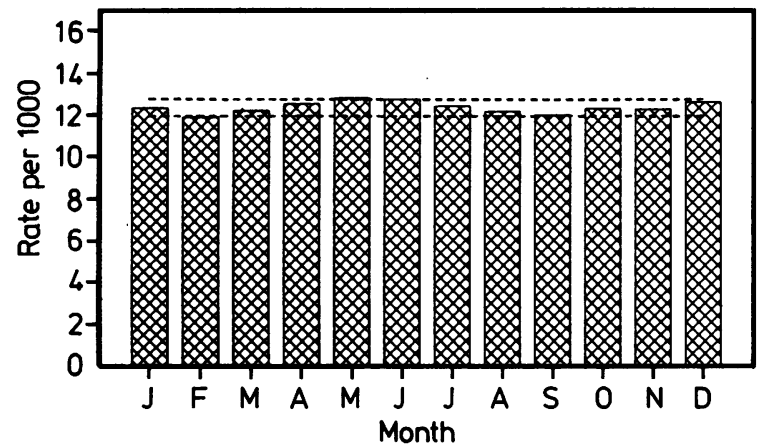

1937 to 1948

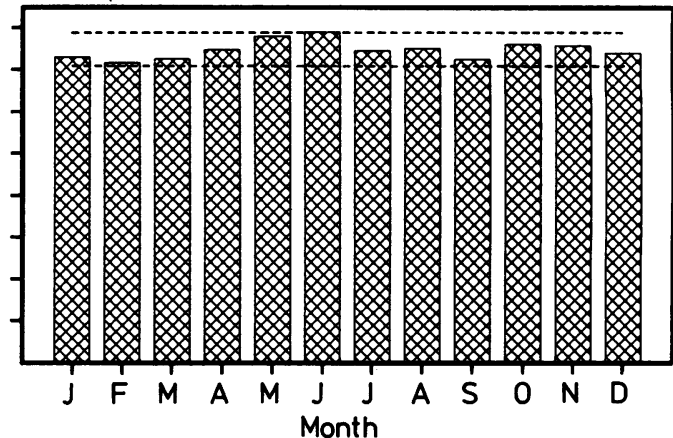

1970 to 1984

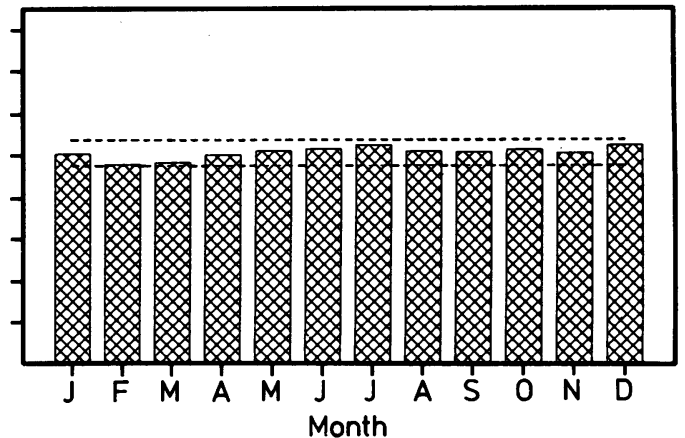

Fig 2 Twin births per 1000 births, Denmark, 1937-84 and subperiods, trend adjusted monthly averages

Table 2 Seasonality in twin births in Denmark according to Edwards', Rogers', and Hewitt's tests

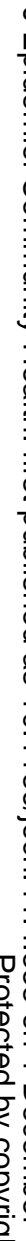

\begin{tabular}{|c|c|c|c|c|c|c|}
\hline \multirow[b]{2}{*}{ Time period } & \multicolumn{2}{|c|}{ Edwards' test } & \multicolumn{2}{|c|}{ Rogers' test } & \multirow{2}{*}{$\begin{array}{l}\text { Hewitt's test } \\
6 \text { months period } \\
\text { highest rank sum }\end{array}$} & \multirow[b]{2}{*}{$p$} \\
\hline & $\overline{x^{2}}$ & $p$ & $\overline{\chi^{2}}$ & $p$ & & \\
\hline $1937-48$ & 0.27 & 0.87 & 0.27 & 0.87 & May-November & 0.066 \\
\hline $1949-69$ & 3.08 & 0.21 & 3.06 & 0.22 & December-May & 0.008 \\
\hline $1970-84$ & 0.35 & 0.84 & 0.35 & 0.84 & May-October & 0.021 \\
\hline 1937-84 & 0.90 & 0.64 & 0.90 & 0.64 & March-August & 0.12 \\
\hline
\end{tabular}

Table 3 Sequential tests of seasonal structure in Danish twinning rates

\begin{tabular}{|c|c|c|c|c|c|c|c|c|c|c|}
\hline \multirow{2}{*}{$\begin{array}{l}\text { Nested } \\
\text { null } \\
\text { hypotheses }\end{array}$} & \multirow{2}{*}{$\begin{array}{l}\text { Degree } \\
\text { of } \\
\text { polynomium }\end{array}$} & \multirow{2}{*}{$\begin{array}{l}\text { Number of } \\
\text { restrictions } \\
\text { NR }\end{array}$} & \multicolumn{4}{|c|}{ Chi-squared test with $N R$ degrees of freedom } & & \\
\hline & & & $\begin{array}{l}1937-48^{*} \\
N R\end{array}$ & $p$ & $\begin{array}{l}1949-69^{*} \\
N R\end{array}$ & $p$ & $\begin{array}{l}1970 \\
N R\end{array}$ & $p$ & $\begin{array}{l}1937 \\
N R\end{array}$ & $p$ \\
\hline $\mathbf{H}_{1}$ & 6 & 5 & 2.95 & 0.71 & 0.64 & 0.99 & $0 \cdot 80$ & 0.98 & 1.74 & 0.88 \\
\hline $\mathrm{H}_{2}$ & 5 & 6 & $3 \cdot 56$ & 0.74 & 2.05 & 0.92 & 0.90 & 0.99 & 1.93 & 0.92 \\
\hline $\mathrm{H}_{3}$ & 4 & 7 & $9 \cdot 10$ & $0 \cdot 25$ & $7 \cdot 11$ & 0.42 & $1 \cdot 34$ & 0.99 & $11 \cdot 16$ & 0.13 \\
\hline $\mathrm{H}_{5}$ & 2 & 9 & 10.85 & 0.29 & $29 \cdot 15$ & 0.0006 & $5 \cdot 66$ & 0.77 & 28.92 & 0.001 \\
\hline $\mathrm{H}_{6}$ & 1 & 10 & 14.53 & 0.15 & $29 \cdot 386$ & 0.001 & $6 \cdot 12$ & 0.81 & $30 \cdot 25$ & 0.001 \\
\hline $\mathrm{H}_{7}$ & 0 & 11 & $15 \cdot 76$ & 0.15 & 35.97 & 0.0002 & $11 \cdot 26$ & 0.42 & $30 \cdot 29$ & 0.002 \\
\hline
\end{tabular}

* Trend adjusted by linear time trend.

** Trend adjusted by third degree time trend polynomial. 
hypothesis tests are 0.014 and 0.0014 , respectively. For these two periods the appropriate seasonal structure is found in the interval between a fifth and a third degree polynomial structure. $\left(\chi_{8}^{2}-\chi_{6}^{2}\right)=\chi_{2}^{2}$ provides a test of the validity of the two additional restrictions implied by a third degree structure relative to a fifth degree structure. We found $\chi^{2}=15.55, \mathrm{df}=2, \mathrm{p}<0.01$ for the total period and $\chi^{2}=10.11, \mathrm{df}=2, \mathrm{p}<0.01$ for the 1949-69 period. Similarly, we can reject the restrictions implied by a fourth degree structure. Hence we infer a seasonal structure in the twinning rate according to a fifth degree polynomial structure for these two periods. For the 1937-48 and 1970-84 periods we cannot reject the null hypothesis of no intra-year variation. The analysis is illustrated graphically in figure 3 for the 1949-69 period.

Table 4 shows the monthly averages in the total period and the 1949-69 subperiod estimated without restrictions and with a fifth degree restriction, respectively. Note that the standard deviations of the latter estimates have decreased by up to $30 \%$.

\section{Discussion}

According to the sequential testing procedure we found a significant seasonality for the subperiod 1949-69 and for the total period 1937-84. This seasonality is following a fifth order polynomial curve, which is not a simple harmonic curve.

This is in agreement with results of Edwards' and Rogers' tests. These tests have high power for seasonality following a simple harmonic sinusoidal pattern but low power for a more complex seasonal structure. Hewitt's test is dependent on the spacing of the peaks. If peaks are separated by six months, the power of the test is high, but low in cases of shorter time spacing between peaks.

It is interesting to note that the decline in twinning rate has stopped, as noted also by Olsen and Rachootin $^{20}$ and Czeizel ${ }^{2}$. The decline has apparently been replaced by a significant and slightly positive trend. Seasonality might reflect the effect of environmental factors influencing reproduction. A lack of seasonality from one time period to another might indicate that these factors are no longer working. The environmental factors causing seasonality might be the ones causing the decline in twinning rate for the years 1949-69.

The secular decline has been noted for dizygotic twinning only. ${ }^{12-14}$ In the same way, seasonality has been described for dizygotic twinning only. ${ }^{23}$ In the present study this distinction between monozygotic and dizygotic twinning was not possible because monthly data for each sex were not available. The
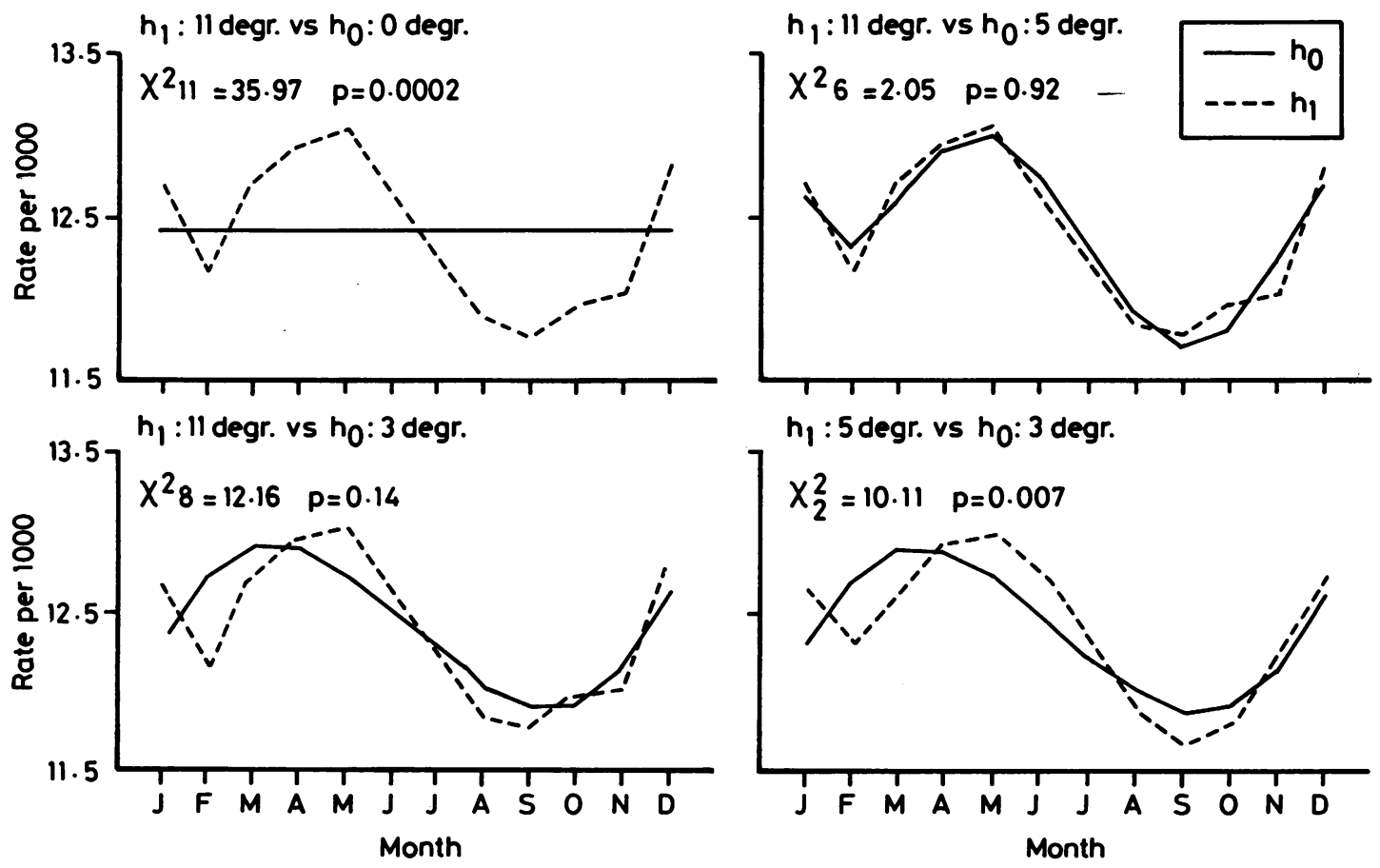

Fig 3 Twin births per 1000 births, Denmark, 1949-69. Analysis of seasonal behaviour under trend control 
Table 4 Monthly trend adjusted averages of twin rates Denmark. (1937-84 average 12.35 per 1000 births)

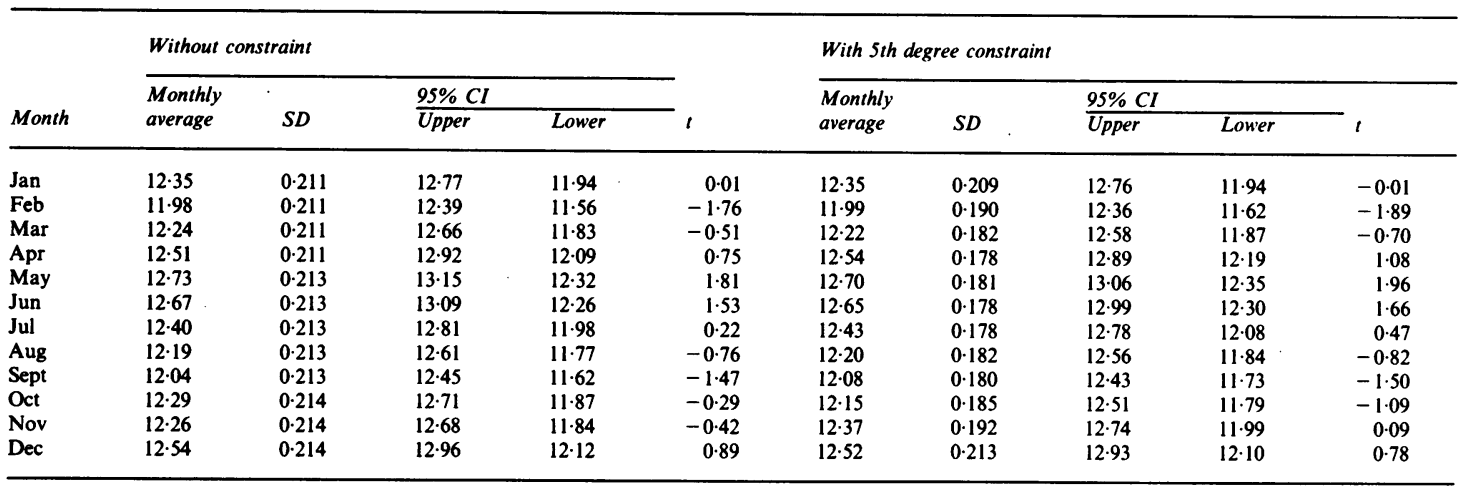

(1949-69 average $12 \cdot 41$ per 1000 births)

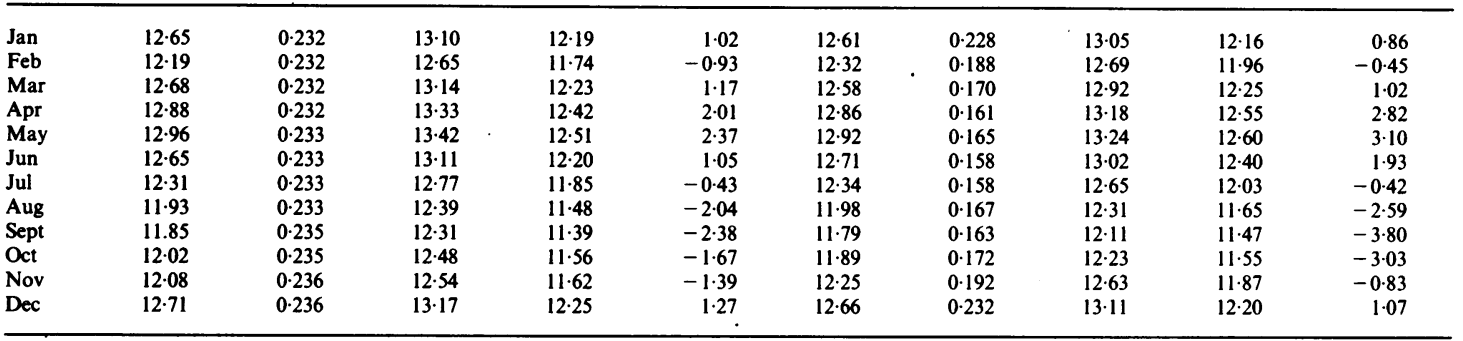

seasonality found in the present study may be caused by the dizygotic twinning only. However, the seasonal variation seems to be strong enough to be significant for the total twin pool. The lack of seasonality for the years 1937-48 and 1970-84 might be caused by the inclusion of both mono- and dizygotic twins.

Many different factors have been mentioned ${ }^{21}$ as possibly influencing season of birth in man: temperature, humidity, sunshine, diet, disease, illegitimacy, abortion, miscarriages, stillbirths, season of marriage, religious observances, festivals, fasts, urbanisation, industrialisation, and restriction of births. James ${ }^{5}$ noted that the dizygotic twinning rate was dependent on the spontaneous abortion rate, the coital rate, the probability of fertilisation of an ovum given that coitus occurred in the fertile period and the probability of double ovulation.

The findings in the literature concerning seasonality of the frequency of spontaneous abortions (recognised abortions) are inconclusive. In some studies seasonality in spontaneous abortion could not be demonstrated. ${ }^{22-24}$ In others, a significant seasonality with a summer maximum was found. ${ }^{25} 26$ If a cyclic trend of that type existed in Denmark for the years concerned, the results would have been a winter maximum in all pregnancies and perhaps a winter minimum with a greater amplitude for twin births.
There seems to be some evidence in the literature for a summer peak in coital rate. $\mathrm{Naeye}^{27}$ found a significant maximum in coital rate in May-June in a study from the USA. Both Parkers ${ }^{28}$ and James ${ }^{29}$ reported on a greater volume of sales of contraceptive material in the summer months than in the winter in England. In some studies seasonal variation with a summer maximum was demonstrated in reported rapes. ${ }^{30}$ Besides, some authors have found a seasonal variation in sexually transmitted diseases (gonorrhoea, syphilis and trichomonas infections) which show a maximum in summer and early autumn, depending on length of incubation. ${ }^{30}$ The existence of a summer maximum of sexual activity may account for some part of the spring peak in twin births in our study.

Nothing is known about the probability of fertilisation, given that coitus occurred in the fertile period.

The probability of double ovulation surely is dependent on the interrelation of the concentrations of sexual, hypophyserean, and hypothalamic hormones. The findings in the literature concerning seasonal variation in these hormones are contradictory. Seasonality in follicle stimulating hormone (FSH) and luteinising hormone ( $\mathrm{LH})$ was demonstrated in adult men $^{33-35}$ but not in adult women. ${ }^{35}$ Circannual 
Seasonality in twin birth rates, Denmark, 1936-84 rhythms in both FSH and LH was demonstrated in both sexes before puberty. ${ }^{36}$

In our searching for some basic aetiological factors leading to the birth of twins we must conclude that seasonality can be documented for some periods in Denmark. The cause of this seasonality is so far unknown. Factors such as dietary intake of certain substances found in fresh food during the summer or increasing amounts of daylight might in the past have been acting through coital rate, rate of spontaneous abortion or perhaps through the frequency of double ovulation. Only an individually based study will make it possible to control the results for factors such as maternal age and parity which are known to increase the chance of dizygotic twins. Elder women with a higher parity might to a greater extent than younger nulliparous women plan their pregnancies so as to deliver in the most favourable season-the spring.

\section{References}

${ }^{1}$ Timonen S, Carper E. Multiple pregnancies and photoperiodicity. Ann Chir Gynaec Fenn 1968; 57: 135-8.

2 Czeizel A. Unexplainable demographic phenomena of multiple births in Hungary. Acta Genet Med Gemellol 1974; 22: 214-8.

${ }^{3}$ Elwood JM. Maternal and environmental factors affecting twin births in Canadian cities. Br J Obstet Gynaecol 1978; 85: 351-8.

4 James WH. Seasonality in twin births. Ann Hum Biol 1976; 3: 193-5.

5 James WH. Seasonality in twin and triplet births. Ann Hum Biol 1980; 7: 163-75.

${ }^{6}$ Edwards J. Season and rate of conception. Nature 1938; 142: 357.

${ }^{7}$ Erhard CL, Nelson FG, Pakter J. Seasonal patterns of conception in New York City. Am J Public Health 1971; 61: $2246-58$

${ }^{8}$ Selvin S, Janerich DT. Seasonal variation in twin births. Nature 1972; 237: 289-90.

${ }^{9}$ Zahalkova M. Multiple births in Southern Moravia. Acta Genet Med Gemellol 1974; 22: 210-13.

${ }^{10}$ Kendler SK, Robinette CD. Month of births by zygosity in the NAS-NRC Twin Registry. Acta Genet Med Gemellol 1983; 32: 113-6.

${ }^{11}$ Kamimura K. Epidemiology of twin births from a climatic point of view. Br J Prev Soc Med 1976; 30: 175-9.

12 Elwood JM. Changes in the twinning rate in Canada 1926-70. Brit J Prev Soc Med 1973; 27: 236-41.

13 Nielsen J, Homma A, Isaksen B, Bertelsen A. Incidence of twin births in Denmark from 1911 to 1974. Acta Genet Med Gemellol 1978; 27: 45-9.

14 Rachootin P, Olsen J. Secular changes in the twinning rate in Denmark 1931 to 1977. Scand J Soc Med 1980; 8: 89-94.

15 Powers WF. Twin pregnancy. Complications and treatment. Obstet Gynecol 1973; 42: 795-808.
${ }^{16}$ Hewitt D, Milner J, Esima A, Pakula A. On Edward's criterion on seasonality and a non-parametric alternative. Brit J Prev Soc Med 1971; 25: 174-6.

${ }^{17}$ Edwards JH. The recognition and estimation of cyclic trends. Ann Hum Genet (Lond) 1961; 25: 83-7.

${ }^{18}$ Rogers JH. A significance test for cyclic trends in incidence data. Biometrika 1977; 64: 152-5.

${ }^{19}$ Søgaard J, Kappel B, Nielsen J. Seasonal analysis of epidemiological time series (in press).

${ }^{20}$ Olsen J, Rachootin P. The end of the decline in twinning rates? Scand J Soc Med 1983; 11 : 119.

${ }^{21}$ Huntington E. Season of birth. Its relations to human abilities. London: John Wiley, 1938.

22 Czeizel E, Elek E. Seasonal changes in the frequency of fetal damages and fertility. Gynecologia 1967; 164 89-95.

${ }^{23}$ Belavalgidad MT. Trend lines and seasonal variations in births and abortions. J Obstet Gynecol (India) 1963; 13: 23-6.

${ }^{24}$ Kovar WR, Taylor RJ. Is spontaneous abortion a seasonal problem? Obstet Gynecol 1960; 16: 350-3.

${ }^{25}$ Hewitt D. A study of temporal variations in the risk of fetal malformation and death. Am J Public Health 1962; 52: 1676-88.

${ }^{26}$ Sandahl B. A study of seasonal and secular trends in incidence of stillbirths and spontaneous abortions in Sweden. Acta Obstet Gynecol Scand 1974; 53: 251-7.

${ }^{27}$ Naeye RL. Seasonal variations in coitus and other risk factors, and the outcome of pregnancy. Early Hum Develop 1980; 4: 61-8.

${ }^{28}$ Parkers AS. Seasonal variation in human sexual activity. In: Thoday JM, Parkers AS, eds. Genetic and environmental influence on behaviour. Edinburgh, 1968; $128-45$.

29 James WH. Social class and season of birth. $J$ Biosoc Sci 1971; 3: 309-20.

${ }^{30}$ Pinatel MC, Cyyba JC, Souchier C. Seasonal changes in sexual hormone secretion, sexual behaviour and sperm production in man. Int $J$ Andrology 1982; 5 (suppl. 5): 183-90.

31 James HW. Coital rates and dizygotic twinning. $J$ Biosoc Science 1972; 4: 101-5.

32 James HW. Coitus-induced ovulation and its implications for estimates of some reproductive parameters. Acta Genet Med Gemellol 1984; 33: 547-55.

${ }^{33}$ Reinberg A, Lagoguey M, Cesselin F, Touitou Y, Legrand JC, Delassale A, Antreassian J, Lagoguey A. Circadian and circannual rhythms in plasma hormones and other variables of five young human males. Acta Endocrinolog 1978; 88: 417-27.

${ }^{34}$ Reinberg A, Lagoguey M. Circadian and circannual rhythms in sexual activity and plasma hormones (FSH, LH, testerone) of five human males. Arch Sexual Behaviour 1978; 7: 13-30.

${ }^{35}$ Halberg F, Haus H, Kuzel M, Lakatua D, Kawasaki T, Ueno $\mathrm{M}$, Uezono $\mathrm{K}$, et al. Cost effective chronobiologic monitoring. In: Albertini A, Prada MD, Peskar BA, eds. Radioimmunoassay of drugs and hormones in cardiovascular medicine. Amsterdam, 1979; 107-20.

${ }^{36}$ Bellastella A, Criscuolo T, Mango A, Perrone L, Sinisi AA, Faggiano M. Circannual rhythms of plasma luteinizing hormone, follicle-stimulating hormone, testerone, prolactin and corticol in prepuberty. Clinical Endocrinol 1983; 19: 453-9. 